\title{
Systemic administration of low dosage of tetanus toxin decreases cell proliferation and neuroblast differentiation in the mouse hippocampal dentate gyrus
}

\author{
Bing Chun Yan ${ }^{1 \#}$, In Hye Kim", Joon Ha Park², Ji Hyeon Ahn², Jeong-Hwi Cho², Bai Hui Chen ${ }^{3}$, Jae-Chul Lee², \\ Jung Hoon Choi ${ }^{4}$, Ki-Yeon Yoo ${ }^{5}$, Choong Hyun Lee ${ }^{6}$, Jun Hwi Cho ${ }^{7}$, Jong-Dai Kim ${ }^{8 *}$, Moo-Ho Won ${ }^{2 *}$ \\ ${ }^{1}$ Department of Integrative Traditional \& Western Medicine, Medical College, Yangzhou University, Yangzhou, China \\ ${ }^{2}$ Department of Neurobiology, and Institute of Medical Sciences, School of Medicine, \\ Kangwon National University, Chuncheon, Korea \\ ${ }^{3}$ Department of Physiology, College of Medicine, and Institute of Neurodegeneration and Neuroregeneration, \\ Hallym University, Chuncheon, Korea \\ ${ }^{4}$ Department of Anatomy, College of Veterinary Medicine, Kangwon National University, Chuncheon, Korea \\ ${ }^{5}$ Department of Oral Anatomy, College of Dentistry and Research institute of Oral Biology, \\ Gangneung-Wonju National University, Gangneung, Korea \\ ${ }^{6}$ Department of Anatomy and Physiology, College of Pharmacy, Dankook University, Cheonan, Korea \\ ${ }^{7}$ Department of Emergency Medicine, and Institute of Medical Sciences, Kangwon National University Hospital, \\ School of Medicine, Kangwon National University, Chuncheon, Korea \\ ${ }^{8}$ Division of Food Biotechnology, School of Biotechnology, Kangwon National University, Chuncheon, Korea
}

\begin{abstract}
In the present study, we investigated the effect of Tetaus toxin (TeT) on cell proliferation and neuroblast differentiation using specific markers: 5-bromo-2-deoxyuridine (BrdU) as an exogenous marker for cell proliferation, $\mathrm{Ki}-67$ as an endogenous marker for cell proliferation and doublecortin (DCX) as a marker for neuroblasts in the mouse hippocampal dentate gyrus (DG) after TeT treatment. Mice were intraperitoneally administered 2.5 and $10 \mathrm{ng} / \mathrm{kg}$ TeT and sacrificed 15 days after the treatment. In both the TeT-treated groups, no neuronal death occurred in any layers of the DG using neuronal nuclei (NeuN, a neuron nuclei maker) and Fluoro-Jade B (F-J B, a high-affinity fluorescent marker for the localization of neuronal degeneration). In addition, no significant change in glial activation in both the 2.5 and $10 \mathrm{ng} / \mathrm{kg}$ TeT-treated-groups was found by GFAP (a marker for astrocytes) and Iba-1 (a marker for microglia) immunohistochemistry. However, in the $2.5 \mathrm{ng} / \mathrm{kg}$ TeT-treated-group, the mean number of BrdU, Ki-67 and DCX immunoreactive cells, respectively, were apparently decreased compared to the control group, and the mean number of each in the $10 \mathrm{ng} / \mathrm{kg}$ TeT-treated-group was much more decreased. In addition, processes of DCX-immunoreactive cells, which projected into the molecular layer, were short compared to those in the control group. In brief, our present results show that low dosage $(10 \mathrm{ng} / \mathrm{kg}) \mathrm{TeT}$ treatment apparently decreased cell proliferation and neuroblast differentiation in the mouse hippocampal DG without distinct gliosis as well as any loss of adult neurons.
\end{abstract}

Key words: Exotoxin, neuronal damage, neurogenesis, sub-granular zone, granule cell

Received 15 May 2013; Revised version received 30 June 2013; Accepted 16 July 2013

\footnotetext{
${ }^{\#}$ These authors contributed equally to this work.

*Corresponding authors: Moo-Ho Won, Department of Neurobiology, School of Medicine, Kangwon National University, Chuncheon 200-701, Korea

Tel: +82-33-250-8891; Fax: +82-33-256-1614; E-mail: mhwon@kangwon.ac.kr

Jong-Dai Kim, Division of Food Biotechnology, School of Biotechnology, Kangwon National University, Chuncheon 200-701, Korea Tel: +82-33-250-6456; E-mail: jongdai@cc.kangwon.ac.kr
}

This is an Open Access article distributed under the terms of the Creative Commons Attribution Non-Commercial License (http://creativecommons.org/licenses/ by-nc/3.0) which permits unrestricted non-commercial use, distribution, and reproduction in any medium, provided the original work is properly cited. 
It has been reported that specific regions, such as the subgranular zone (SGZ) of the dentate gyrus (DG) and the subventricular zone (SVZ) of the lateral ventricle, in the brain exhibit self-renewal activity throughout the animal's life span [1-4]. It is well known that brain disorders and environmental factors can affect neurogenesis and gliogenesis in some neurogenic regions such as the hippocampus [5-8]. The hippocampus, which is involved in cognitive processes such as learning and memory, is susceptible to neurological disorders such as Alzheimer's disease [9,10].

Cells newly generated in the hippocampus, which are mainly located in the SGZ of the DG, can migrate into the granule cell layer of the DG where they mature into new neurons and make functional synaptic connections with the hippocampal circuitry [11-13].

Tetanus toxin (TeT), one of the most toxic substances to humans, can cause tetanus [14]. TeT is an A-B type of toxin with a molecular mass of $150 \mathrm{kDa}$, including a light chain $(50 \mathrm{kDa})$ and heavy chain $(100 \mathrm{kDa})$ subunit [15-18]. Basically, the light chain subunit exits from the endosome and undergoes retrograde transport via the nerve axon to the spinal cord. The heavy chain subunit mediates the inhibition of the release of neurotransmitters (e.g., glycine and GABA) from the inhibitory interneurons into the synaptic cleft resulting in the inability of contracted muscles to relax $[17,19]$. It has been known that adult rats treated with TeT show spatial learning deficits [20].

It has been suggested that the loss of hippocampal neurons produces deficits in learning and memory [2123]. In addition, injection of high dosage (1000 mouse minimum lethal doses) of TeT into the rat hippocampus induces neuronal loss in the granule cells of the rat DG [24]. However, there are no studies regarding changes of cell proliferation and neuroblast differentiation in the hippocampal DG after systemic administration of TeT. In the present study, therefore, we investigated neuronal damage and glial changes in the mouse DG after systemic administration of TeT using neuronal nuclei (NeuN, a neuron nuclei maker), Fluoro-Jade B (F-J B, a high affinity fluorescent marker for the localization of neuronal degeneration), glial fibrillary acidic protein (GFAP, a marker for astrocytes) and ionized calciumbinding adapter molecule (Iba-1, a marker for microglia). We also examined effects of TeT treatment on cell proliferation and neuroblast differentiation in the mouse DG using 5-bromo-2-deoxyuridine (BrdU, an exogenous marker for cell proliferation), Ki-67 (an endogenous marker for cell proliferation) and doublecortin (DCX, a marker for neuroblasts).

\section{Materials and Methods}

\section{Experimental animals}

The present study used the progeny of male ICR mice (B.W., 25-30 g; 8 weeks of age) which were purchased from the Jackson Laboratory (Maine, ME). The animals were housed in a conventional state under adequate temperature $\left(23 \pm 3^{\circ} \mathrm{C}\right)$ and relative humidity $(55 \pm 5 \%)$ control with a 12-h light/12-h dark cycle, and provided with free access to food and water. All animal care and experimental procedures conformed to the NIH guidelines (NIH Guide for the Care and Use of Laboratory Animals, NIH Publication No. 85-23, 1985); the animal protocol used in the present study was reviewed and approved based on ethical procedures and scientific care by the Kangwon National University-Institutional Animal Care and Use Committee (KIACUC-12-0018). All efforts were made to minimize animal suffering, as well as, the number of the animals used.

\section{Treatment of TeT and BrdU labeling.}

The mice (total 42 mice) was intraperitoneally injected once with $2.5(n=14)$ or $10 \mathrm{ng} / \mathrm{kg}(n=14)$ of TeT, and the control animals $(n=14)$ were injected with the same volume of saline ( $\mathrm{pH} 7.4)$. The mice were then killed at 15 days after TeT-treatment.

On the other hand, after Tet-treatment, all the animals were treated immediately with $50 \mathrm{mg} / \mathrm{kg}$ BrdU (Sigma, St. Louis, MO) by intraperitoneal injection: BrdU was administrated 3 times at $8 \mathrm{~h}$ intervals.

\section{Tissue processing for histology}

For the histological analysis, animals (total 21 animals, $n=7$ in each group) were anesthetized with sodium pentobarbital and perfused transcardially with $0.1 \mathrm{M}$ phosphate-buffered saline (PBS, pH 7.4) followed by $4 \%$ paraformaldehyde in $0.1 \mathrm{M}$ phosphate-buffer (PB, $\mathrm{pH}$ 7.4). The brains were removed and postfixed in the same fixative for $6 \mathrm{~h}$. The brain tissues were cryoprotected by infiltration with $30 \%$ sucrose overnight. Thereafter frozen tissues were serially sectioned on a cryostat (Leica, Wetzlar, Germany) into $30-\mu \mathrm{m}$ coronal sections, and they were then collected into six-well plates containing PBS. 


\section{F-J B histofluorescence}

To confirm the neuronal death in the hippocampus after TeT treatment, control- and TeT-treated animals were used for Fluoro-Jade B (F-J B, a high affinity fluorescent marker for the localization of neuronal degeneration) histofluorescence under the same conditions. F-J B histofluorescence staining procedures were conducted according to the method by previous study. [25]. In brief, the sections were first immersed in a solution containing $1 \%$ sodium hydroxide in $80 \%$ alcohol, and followed in $70 \%$ alcohol. They were then transferred to a solution of $0.06 \%$ potassium permanganate, and transferred to a $0.0004 \%$ F-J B (Histochem, Jefferson, AR, USA) staining solution. After washing, the sections were placed on a slide warmer (approximately $50^{\circ} \mathrm{C}$ ), and then examined using an epifluorescent microscope (Carl Zeiss, Germany) with blue (450-490 $\mathrm{nm}$ ) excitation light and a barrier filter. With this method neurons that undergo degeneration brightly fluoresce in comparison to the background [26].

\section{Immunohistochemistry for NeuN, GFAP, Iba-1, BrdU, Ki-67 and DCX}

To obtain the accurate data for immunohistochemistry, the sections from control- and TeT-treated-animals were used under the same conditions. Firstly, DNA denaturation was conducted, and the sections were incubated in $2 \mathrm{~N}$ $\mathrm{HCl}$ and in boric acid (only for BrdU staining). The sections were sequentially treated with $0.3 \%$ hydrogen peroxide (H2O2) in PBS for $30 \mathrm{~min}$ and 10\% normal goat serum in $0.05 \mathrm{M}$ PBS for $30 \mathrm{~min}$. They were diluted mouse anti-NeuN (1:1000, Chemicon) to detect the neuron nuclei, mouse anti-GFAP (1:800, Chemicon) to detect the astrocytes, mouse anti-BrdU (1:200, Chemicon International), rabbit anti-Iba-1 (1:500, Wako) to detect the microglia, rabbit anti-Ki-67 (1:100, Wako) to detect the cell proliferation, goat-anti-DCX $(1: 100$, santa cruz $)$ to detect the neuroblast differentiation overnight at $4^{\circ} \mathrm{C}$ and subsequently exposed to biotinylated goat antimouse, rabbit, rabbit anti- goat $\operatorname{IgG}$ and streptavidin peroxidase complex (diluted 1:200, Vector, Burlingame, $\mathrm{CA})$. They were then visualized by reacting to 3,3'diaminobenzidine tetrachloride (Sigma) in $0.1 \mathrm{M}$ Tris$\mathrm{HCl}$ buffer ( $\mathrm{pH}$ 7.2) and mounted on gelatin-coated slides. After dehydration the sections were mounted in canada balsam (Kanto Chemical, Japan). In order to establish the specificity of the immunostaining, a negative control test was carried out with pre-immune serum instead of primary antibody. The negative control resulted in the absence of immunoreactivity in all structures. To elucidate the effects of TeT on cell proliferation and neuroblast differentiation in mice, total number of BrdU, Ki-67 and DCX positive cells in all the groups were counted in the DG in 15 sections/each animal using an image analyzing system equipped with a computer-based CCD camera (software: Optimas 6.5, CyberMetrics, Scottsdale, AZ). Cell counts were obtained by averaging the counts from the sections taken from each animal.

\section{Western blot analysis}

To obtain the accurate data for change in DCX levels in the hippocampus after TeT treatment, control- and TeT-treated-animals (total 21 animals, $n=7$ in each group) were used for western blot analysis. After sacrificing them and removing the brain, it was serially and transversely cut into a thickness of $400 \mu \mathrm{m}$ on a vibratome (Leica), and the hippocampal DG region was then dissected with a surgical blade. The tissues were homogenized in $50 \mathrm{mM}$ PBS (pH 7.4) containing 0.1 $\mathrm{mM}$ ethylene glycol bis (2-aminoethyl Ether)-N,N,N',N' tetraacetic acid (EGTA) (pH 8.0), 0.2\% Nonidet P-40, 10 $\mathrm{mM}$ ethylendiamine tetraacetic acid (EDTA) ( $\mathrm{pH} \mathrm{8.0),}$ $15 \mathrm{mM}$ sodium pyrophosphate, $100 \mathrm{mM} \beta$-glycerophosphate, $50 \mathrm{mM} \mathrm{NaF}, 150 \mathrm{mM} \mathrm{NaCl}, 2 \mathrm{mM}$ sodium orthovanadate, $1 \mathrm{mM}$ phenylmethylsulfonyl fluoride (PMSF) and $1 \mathrm{mM}$ dithiothreitol (DTT). After centrifugation, the protein level in the supernatants was determined using a Micro BCA protein assay kit with bovine serum albumin as a standard (Pierce Chemical, Rockford, IL). Aliquots containing $50 \mu \mathrm{g}$ of total protein were boiled in loading buffer containing $150 \mathrm{mM}$ Tris ( $\mathrm{pH}$ 6.8), $3 \mathrm{mM}$ DTT, 6\% SDS, $0.3 \%$ bromophenol blue and 30\% glycerol. The aliquots were then loaded onto a $5 \%$ polyacrylamide gel. After electrophoresis, the gels were transferred to nitrocellulose membranes (Pall Crop, East Hills, NY). To reduce background staining, the membranes were incubated with $5 \%$ non-fat dry milk in PBS containing $0.1 \%$ Tween 20 for $45 \mathrm{~min}$, followed by incubation with goat-anti-DCX (1:200, santa cruz), peroxidase-conjugated rabbit anti-goat IgG (Sigma) and an ECL kit (Pierce Chemical). The result of western blot analysis was scanned, and densitometric analysis for the quantification of the bands was done using Scion Image software (Scion Corp., Frederick, MD), which was used to count relative optical density (ROD): A ratio of the 
ROD was calibrated as $\%$, with sham-group designated as $100 \%$.

\section{Statistical analysis}

The data shown here represent the means \pm SEM. Differences among the means were statistically analyzed by Student $t$-test in order to elucidate the changes of cell proliferation and neuroblast in the control and TeTtreated groups. In addition, differences of the mean number among the groups were statistically analyzed by analysis of variance (ANOVA) followed by Post Hoc test in order to elucidate the differences among experimental groups. Statistical significance was considered at $P<0.05$.

\section{Results}

\section{Neuronal damage}

NeuN-immunoreactive cells: Neuronal distribution in the mouse DG after TeT treatment was examined by NeuN immunohistochemistry (Figure 1A-1C). In the control group, NeuN-immunoreactive cells were well detected in all the layers of the DG (Figure 1A). In both the 2.5 and $10 \mathrm{ng} / \mathrm{kg}$ TeT-treated-groups, NeuNimmunoreactive cells were similar to those of the control group (Figure 1B, 1C).

F-J B-positive cells: Neuronal damage in the DG after TeT treatment was examined by F-J B histofluorescence
(Figure 1D-1F). In both the control- and TeT-treatedgroups, F-J B positive cells were hardly detected in any layers of the DG (Figure 1D-1F).

\section{Gliosis}

Gliosis in the DG after TeT treatment was observed by GFAP and Iba-1 immunohistochemistry (Figure 1G-1L). No obvious changes in GFAP-immunoreactive astrocytes in both the control and TeT-treated-groups (Figure 1G1I) were detected; in the $10 \mathrm{ng} / \mathrm{kg}$ TeT-treated group, microglia were slightly activated near the granule cell layer compared to that in the control group (Figure 1J1L).

\section{Cell proliferation}

BrdU-immunoreactive cells: BrdU-immunoreactive cells were mainly detected in the SGZ of the DG. In the control group, many BrdU-immunoreactive cells were observed (Figure 2A, 2D): the mean number of BrdUimmunoreactive cells was $19.25 \pm 1.7$ per section of the DG (Figure 2G). However, in the $2.5 \mathrm{ng} / \mathrm{kg}$ TeT-treatedgroup, BrdU-immunoreactive cells were decreased compared to the control group (Figure 2B, 2E); the mean number of them was $11.5 \pm 2.1$ per section of the DG (Figure 1G). BrdU-immunoreactive cells were much more decreased in the $10 \mathrm{ng} / \mathrm{kg}$ group than the $2.5 \mathrm{TeT}$ treated-group (Figure 2C, $2 \mathrm{~F}$ ); the mean number of them was $4.75 \pm 1.7$ per section of the DG (Figure $1 G$ ).
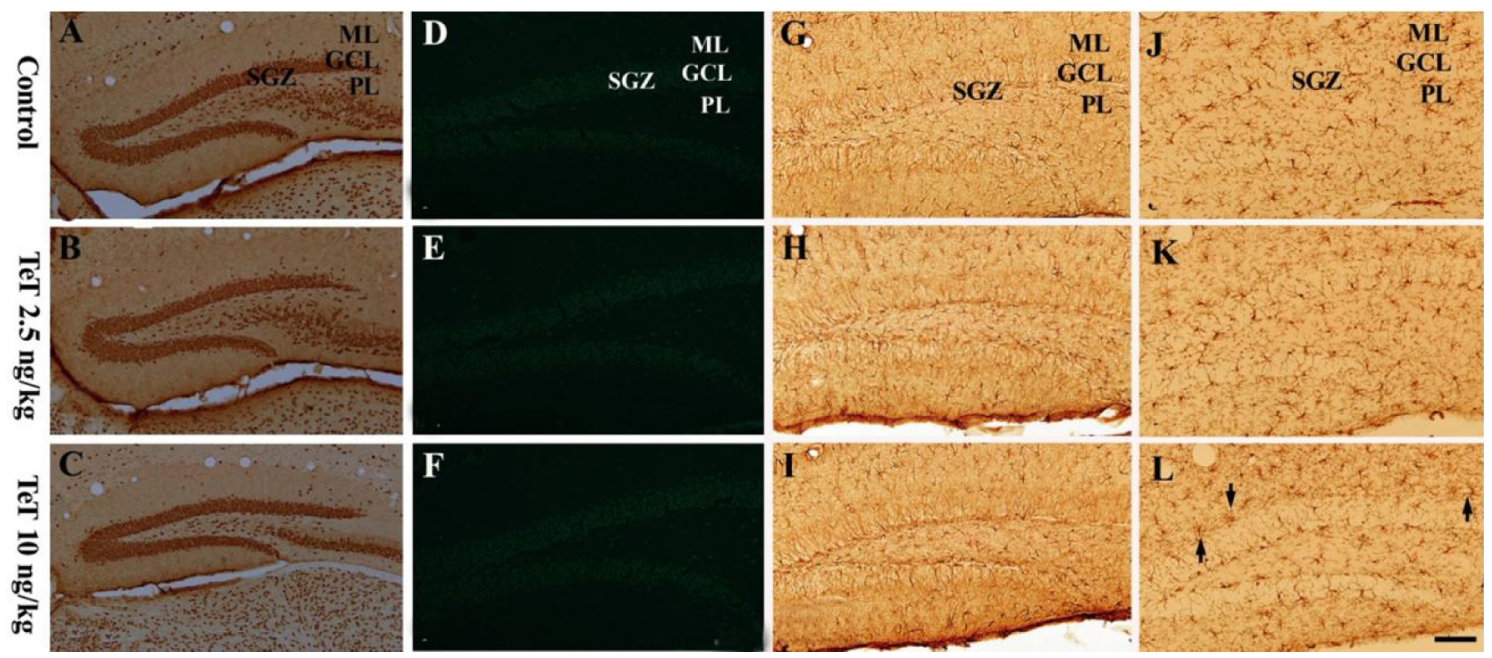

Figure 1. NeuN immunohistochemistry (A-C), F-J B histofluorescence (D-F), GFAP immunohistochemistry (G-I) and Iba-1 immunohistochemistry (J-L) in the mouse DG of the control-, 2.5 and $10 \mathrm{ng} / \mathrm{kg}$ TeT-treated-groups. The distribution of NeuNimmunoreactive cells in the TeT-treated-groups is similar to that in the control group. F-J B-positive cells are hardly detected in the DG of all the experimental groups. Microglia are slightly activated (arrows) in the $10 \mathrm{ng} / \mathrm{kg}$ TeT-treated-group. ML, molecular layer; GCL, granule cell layer; PL, polymorphic layer; SGZ, subgranular zone. Scale bar=100 $\mu \mathrm{m}$. 

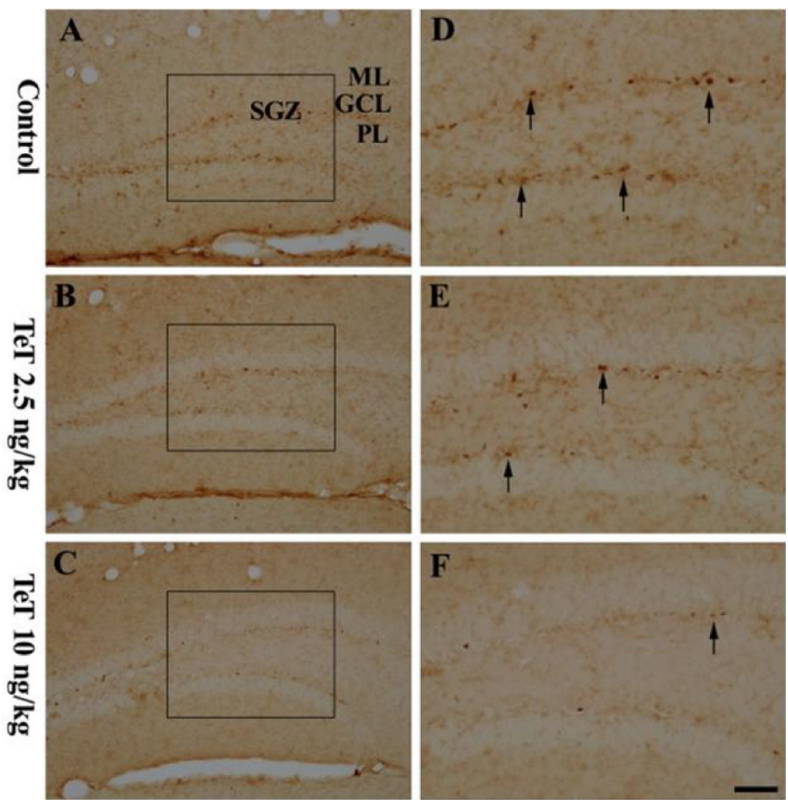

G

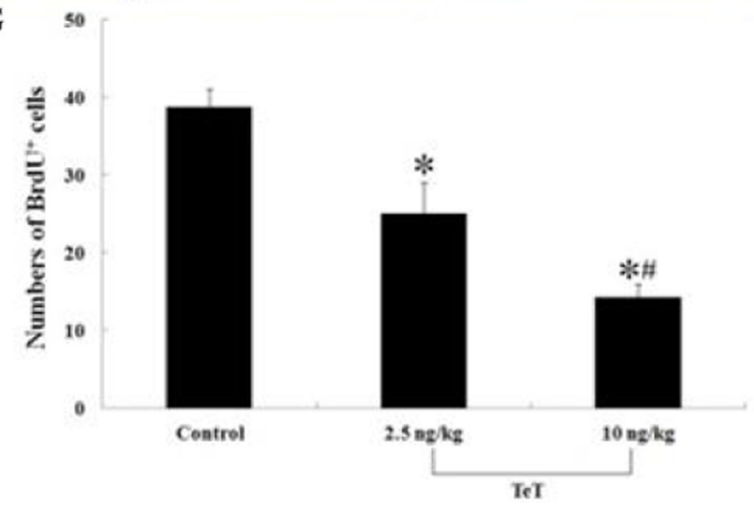

Figure 2. BrdU immunohistochemistry in the mouse DG in the control- (A and D), $2.5 \mathrm{ng} / \mathrm{kg} \mathrm{TeT-}(B$ and $E)$ and $10 \mathrm{ng} / \mathrm{kg} \mathrm{TeT}$ ( $D$ and $F$ )-treated-groups. BrdU-positive $\left(^{+}\right)$cells (arrows) are distinctively decreased in the $10 \mathrm{ng} / \mathrm{kg}$ TeT-treated-group. ML, molecular later; GCL, granule cell layer; PL, polymorphic layer; SGZ, subgranular zone. Scale bar=50 im. G: The mean number of $\mathrm{BrdU}^{+}$cells per section in the control- and TeTtreated-groups ( $n=7$ per group; $\mathrm{F}=62.14 ;{ }^{*} P<0.05$ : significantly different from the control group, ${ }^{\#} P<0.05$, significantly different from the preceding group). The bars indicate the means \pm SEM.

Ki-67-immunoreactive cells: Ki-67-immunoreactive cells were also mainly detected in the SGZ of the DG. In the control group, Ki-67-immunoreactive cells were easily observed (Figure 3A, 3D); the mean number of Ki-67-immunoreactive cells was $32.75 \pm 3.3$ per section (Figure 3G). However, Ki-67-immunoreactive cells in the 2.5 and $10 \mathrm{ng} / \mathrm{kg}$ TeT-treated-groups gradually decreased with TeT dosage (Figure 3B, 3C, 3E, 3F); the mean number of Ki-67-immunoreactive cells were $17 \pm 2.1$ and $12.25 \pm 2.2$ per section, respectively (Figure $3 \mathrm{G})$.
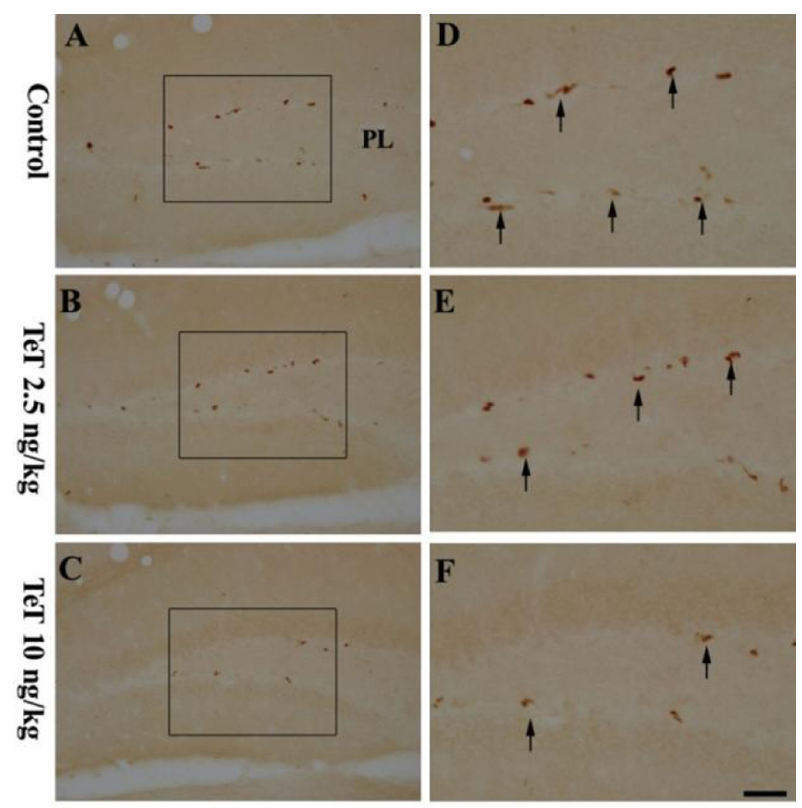

G

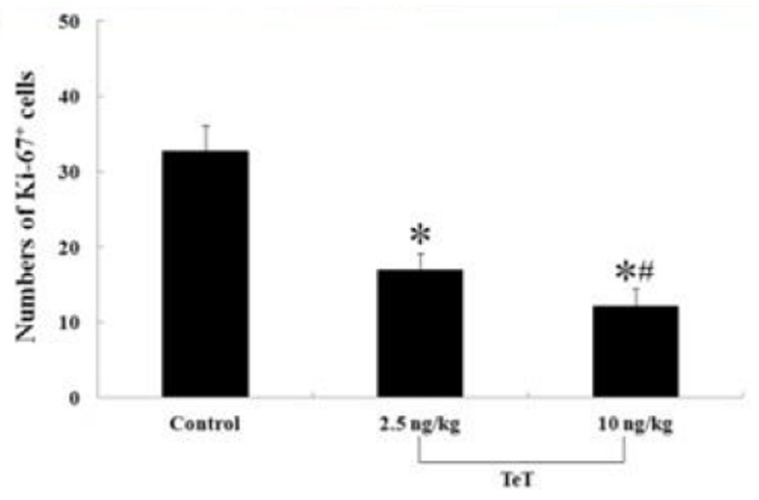

Figure 3. Ki-67 immunohistochemistry in the mouse DG of the control- (A and D), $2.5 \mathrm{ng} / \mathrm{kg}$ TeT (B and E)- and $10 \mathrm{ng} / \mathrm{kg} \mathrm{TeT}$ $\left(\mathrm{C}\right.$ and $\mathrm{F}$ )-treated-groups. Ki-67-immunoreactive $\left(^{+}\right)$cells (arrows) are apparently decreased in the $10 \mathrm{ng} / \mathrm{kg}$ TeT-treatedgroup. ML, molecular later; GCL, granule cell layer; PL, polymorphic layer; SGZ, subgranular zone. Scale bar=50 ìm. $\mathrm{G}$ : The mean number of $\mathrm{Ki}-67^{+}$cells per section in the controland TeT-treated-groups ( $n=7$ per group; $\mathrm{F}=67.40 ;{ }^{*} P<0.05$ : significantly different from the control group, ${ }^{\#} P<0.05$, significantly different from the preceding group). The bars indicate the means $\pm S E M$.

\section{Neuroblast differentiation}

In the control group, DCX-immunoreactive neuroblasts were easily observed in the DG (Figure 4A, 4D); their cell bodies were located in the SGZ and their processes projected into the molecular layer of the DG. In this group, the mean number of DCX-immunoreactive neuroblasts was $69.25 \pm 5.8$ per section of the DG (Figure 4G). In the $2.5 \mathrm{ng} / \mathrm{kg}$ TeT-treated-group, DCXimmunoreactive cells were decreased in number and their processes became very short (Figure 4B,4E), and 

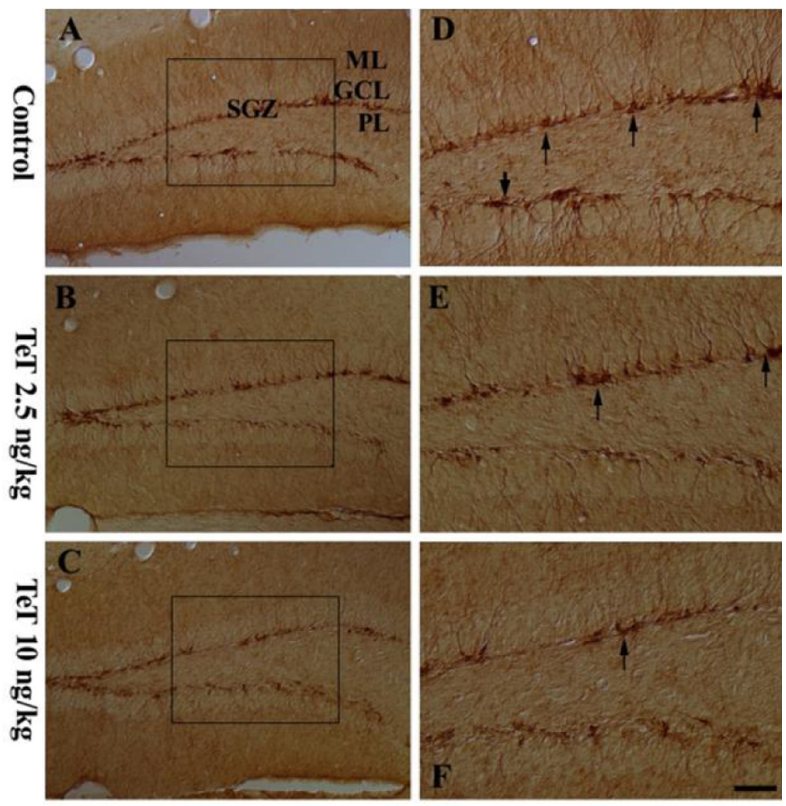

G

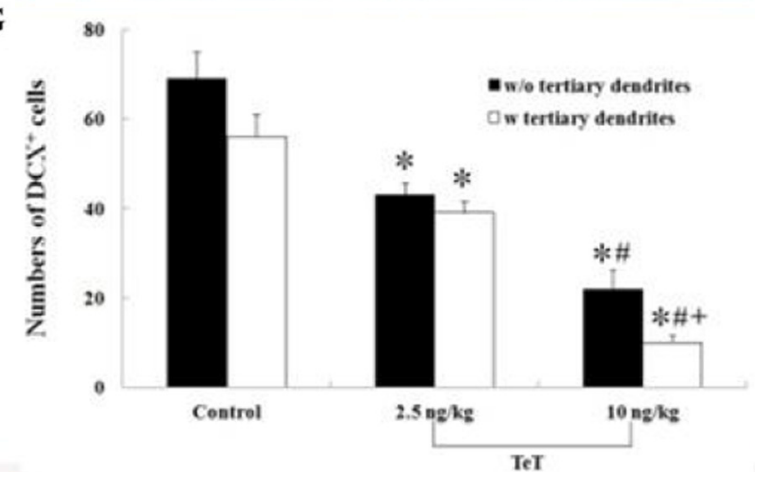

Figure 4. DCX immunohistochemistry in the mouse DG of the control- (A and D), $2.5 \mathrm{ng} / \mathrm{kg}$ TeT (B and E)- and $10 \mathrm{ng} / \mathrm{kg} \mathrm{TeT}$ (C and F)-treated-groups. DCX-immunoreactive $\left(^{+}\right)$cells (arrows) are significantly decreased in the $10 \mathrm{ng} / \mathrm{kg} \mathrm{TeT-}$ treated-group. ML, molecular later; GCL, granule cell layer; $\mathrm{PL}$ polymorphic layer; SGZ, subgranular zone. Scale bar=50 im. $\mathrm{G}$ : The mean number of $\mathrm{DCX}^{+}$cells per section in the controland TeT-treated-groups ( $n=7$ per group; $\mathrm{F}=112.44 ;{ }^{*} P<0.05$ significantly different from the control group, ${ }^{\#} P<0.05$ significantly different from the preceding group ${ }^{+} P<0.05$, significantly different from the w/o tertiary dendrites group). The bars indicate the means \pm SEM.

the number of them was $40.5 \pm 2.6$ per section of the DG (Figure $3 \mathrm{G}$ ). In the $10 \mathrm{ng} / \mathrm{kg}$ TeT-treated-group, the mean number of DCX-immunoreactive cells was $22 \pm 4.3$ per section of the DG, and their processes were much shorter and fewer in number than those in the $2.5 \mathrm{ng} / \mathrm{kg}$ TeT-treated-group (Figure 4C, 4F, 4G).

\section{DCX protein levels}

Western blot analysis showed that the levels of DCX were distinctively changed in the mouse hippocampal DG after $2.5 \mathrm{ng} / \mathrm{kg}$ and $10 \mathrm{ng} / \mathrm{kg}$ TeT treatment (Figure
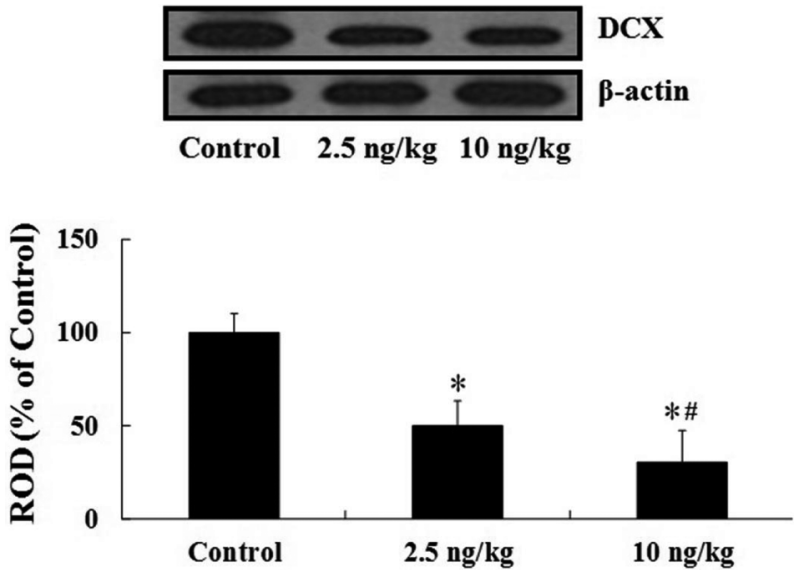

Figure 5. Western blot analysis of DCX in the mouse DG derived from the control-, 2.5 and $10 \mathrm{ng} / \mathrm{kg}$ TeT-treated-groups ( $n=7$ in each group). The relative optical density (ROD) of immunoblot bands are demonstrated as percent values $\left({ }^{*} P<0.05\right.$, significantly different from the control group, ${ }^{\#} P<0.05$, significantly different from the preceding group). The bars indicate the means \pm SEM.

5). In the $2.5 \mathrm{ng} / \mathrm{kg}$ TeT-treated-group, DCX protein level was decreased to about $50 \%$ of the control group. DCX protein level in the $10 \mathrm{ng} / \mathrm{kg}$ TeT-treated-group was much more decreased (about $30 \%$ of the control group).

\section{Discussion}

The hippocampus is an area vulnerable to neuronal damage induced by neurodegenerative disorders, and shows morphological and functional changes as well as some neuropathological and neurochemical alterations [27-29].

It was reported that $\mathrm{Te} T$ reduces monosynaptic inhibitory and excitatory synaptic transmission in mouse spinal cord neurons in culture [30]. In addition, TeT blocked the excitatory transmission that is primarily transported via sensory neurons [31]. Furthermore, it is well known that that TeT induces seizures and easily causes microglial activation in the hippocampus [32,33].

It was reported that there was a loss of granule cells in the rat hippocampal DG 7 days after high dosage (1000 mouse minimum lethal doses) of TeT injection using cresyl fast violet staining $[24,34,35]$. In the present study, however, we did not detect any neuronal loss or damage in the mouse DG until 15 days after low dosage (2.5 or $10 \mathrm{ng} / \mathrm{kg}$ ) of TeT treatment using NeuN immunohistochemistry and F-J B histofluorescence. We also examined for significant changes in glial activation but 
these were not found in the DG after of TeT treatment. These results are supported by a previous study which showed that injection of $2 \mathrm{ng}$ of TeT into the CA3 subfield of the infant rat hippocampus proper did not cause any hippocampal neuronal death until 3 months later, although the density of hematoxylin and eosinstained neurons was significantly decreased in the stratum pyramidale [36].

The hippocampus is involved in learning and memory, and the generation of new hippocampal neurons has been suggested to be a new form of plasticity implicated in these processes [37,38]. It has been indicated that the acquisition of spatial memory requires hippocampal neurogenesis, especially in the DG $[39,40]$. Lee et al. (2001) reported that rats treated with $2 \mathrm{ng}$ of TeT were markedly deficient in learning using the Morris water maze task [36]. Later, some researchers showed that impaired recognition memory is closely related to reduced hippocampal neurogenesis [38,41].

In the present study, we observed cell proliferation in the DG using BrdU and $\mathrm{Ki}-67$ and neuroblast differentiation using DCX. We found that they were markedly reduced in the $10 \mathrm{ng} / \mathrm{kg}$ TeT-treated-group than in the $2.5 \mathrm{ng} / \mathrm{kg}$ TeT-treated-group; that is, cell proliferation and neuroblast differentiation were gradually decreased in a dose-dependent manner with increasing doses of TeT. This finding is similar to the results of previous studies which showed that lipopolysaccharide (LPS), a typical endotoxin, could easily induce brain inflammation and caused reduced neurogenesis in the adult brain $[42,43]$.

In brief, our present findings demonstrate that a low dosage of TeT treatment apparently decreases cell proliferation and neuroblast differentiation in the mouse hippocampal DG without distinct gliosis as well as any neuronal loss/damage.

\section{Acknowledgments}

The authors would like to thank Mr. Sung Uk Lee for his technical help in this study. This research was supported by the National Research Foundation of Korea (NRF) funded by the Ministry of Education, Science and Technology (2010-0010580), and by Basic Science Research Program through the National Research Foundation of Korea (NRF) funded by the Ministry of Education, Science and Technology (NO2011-0022812).

\section{References}

1. Colditz MJ, Catts VS, Al-menhali N, Osborne GW, Bartlett PF, Coulson EJ. p75 neurotrophin receptor regulates basal and fluoxetine-stimulated hippocampal neurogenesis. Exp Brain Res 2010; 200(2): 161-167.

2. Helfer JL, Goodlett CR, Greenough WT, Klintsova AY. The effects of exercise on adolescent hippocampal neurogenesis in a rat model of binge alcohol exposure during the brain growth spurt. Brain Res 2009; 1294: 1-11.

3. Li WL, Fraser JL, Yu SP, Zhu J, Jiang YJ, Wei L. The role of VEGF/VEGFR2 signaling in peripheral stimulation-induced cerebral neurovascular regeneration after ischemic stroke in mice. Exp Brain Res 2011; 214(4): 503-513.

4. Shook BA, Manz DH, Peters JJ, Kang S, Conover JC. Spatiotemporal changes to the subventricular zone stem cell pool through aging. J Neurosci 2012; 32(20): 6947-6956.

5. Crews FT, Boettiger CA. Impulsivity, frontal lobes and risk for addiction. Pharmacol Biochem Behav 2009; 93(3): 237-247.

6. Hong XP, Peng CX, Wei W, Tian Q, Liu YH, Cao FY, Wang Q, Wang JZ. Relationship of adult neurogenesis with tau phosphorylation and GSK-3â activity in subventricular zone. Neurochem Res 2011; 36(2): 288-296.

7. Kalluri HS, Dempsey RJ. IGFBP-3 inhibits the proliferation of neural progenitor cells. Neurochem Res 2011; 36(3): 406-411.

8. Lou SJ, Liu JY, Chang H, Chen PJ. Hippocampal neurogenesis and gene expression depend on exercise intensity in juvenile rats. Brain Res 2008; 1210: 48-55.

9. Brinton RD, Wang JM. Therapeutic potential of neurogenesis for prevention and recovery from Alzheimer's disease: allopregnanolone as a proof of concept neurogenic agent. Curr Alzheimer Res 2006; 3(3): 185-190.

10. Bruel-Jungerman E, Rampon C, Laroche S. Adult hippocampal neurogenesis, synaptic plasticity and memory: facts and hypotheses. Rev Neurosci 2007; 18(2): 93-114.

11. Dayer AG, Ford AA, Cleaver KM, Yassaee M, Cameron HA Short-term and long-term survival of new neurons in the rat dentate gyrus. J Comp Neurol 2003; 460(4): 563-572.

12. Gage FH. Mammalian neural stem cells. Science 2000; 287(5457): 1433-1438.

13. Tanapat P, Hastings NB, Reeves AJ, Gould E. Estrogen stimulates a transient increase in the number of new neurons in the dentate gyrus of the adult female rat. J Neurosci 1999; 19(14): 5792-5801.

14. Yeh FL, Dong M, Yao J, Tepp WH, Lin G, Johnson EA, Chapman ER. SV2 mediates entry of tetanus neurotoxin into central neurons. PLoS Pathog 2010; 6(11): e1001207.

15. Behrensdorf-Nicol HA, Kegel B, Bonifas U, Silberbach K, Klimek J, Weiber K, Krämer B. Residual enzymatic activity of the tetanus toxin light chain present in tetanus toxoid batches used for vaccine production. Vaccine 2008; 26(31): 3835-3841.

16. Goonetilleke A, Harris JB. Clostridial neurotoxins. J Neurol Neurosurg Psychiatry 2004; 75 Suppl 3: iii35-39.

17. Indrawattana N, Sookrung N, Kulkeaw K, Seesuay W, Kongngoen T, Chongsa-nguan M, Tungtrongchitr A, Chaicumpa W. Human monoclonal $\mathrm{ScFv}_{\mathrm{v}}$ that inhibits cellular entry and metalloprotease activity of tetanus neurotoxin. Asian Pac J Allergy Immunol 2010; 28(1): 85-93.

18. Kobayashi T, Kai N, Kobayashi K, Fujiwara T, Akagawa K, Onda M, Kobayashi K. Transient silencing of synaptic transmitter release from specific neuronal types by recombinant tetanus toxin light chain fused to antibody variable region. J Neurosci Methods 2008; 175(1): 125-132.

19. Shapiro RE, Specht CD, Collins BE, Woods AS, Cotter RJ, Schnaar RL. Identification of a ganglioside recognition domain of tetanus toxin using a novel ganglioside photoaffinity ligand. J Biol Chem 1997; 272(48): 30380-30386.

20. Mellanby J, George G. Tetanus toxin and experimental epilepsy in 
rats. Adv Cytopharmacol 1979; 3: 401-408.

21. Rausch R, Babb TL. Hippocampal neuron loss and memory scores before and after temporal lobe surgery for epilepsy. Arch Neurol 1993; 50(8): 812-817.

22. Huang Y, Shi X, Xu H, Yang H, Chen T, Chen S, Chen X. Chronic unpredictable stress before pregnancy reduce the expression of brain-derived neurotrophic factor and N-methyl-D-aspartate receptor in hippocampus of offspring rats associated with impairment of memory. Neurochem Res 2010; 35(7): 1038-1049.

23. Rajan KE, Singh HK, Parkavi A, Charles PD. Attenuation of 1(m-chlorophenyl)-biguanide induced hippocampus-dependent memory impairment by a standardised extract of Bacopa monniera (BESEB CDRI-08). Neurochem Res 2011; 36(11): 2136-2144.

24. Bagetta G, Corasaniti MT, Nisticó G, Bowery NG. Behavioural and neuropathological effects produced by tetanus toxin injected into the hippocampus of rats. Neuropharmacology 1990; 29(8): 765-770.

25. Candelario-Jalil E, Alvarez D, Merino N, León OS. Delayed treatment with nimesulide reduces measures of oxidative stress following global ischemic brain injury in gerbils. Neurosci Res 2003; 47(2): 245-253.

26. Schmued LC, Hopkins KJ. Fluoro-Jade B: a high affinity fluorescent marker for the localization of neuronal degeneration. Brain Res 2000; 874(2): 123-130.

27. Arushanyan EB, Beier EV. The hippocampus and cognitive impairments. Neurosci Behav Physiol 2008; 38(8): 751-758.

28. Leiva J, Palestini M, Infante C, Goldschmidt A, Motles E. Copper suppresses hippocampus LTP in the rat, but does not alter learning or memory in the morris water maze. Brain Res 2009; 1256: 6975 .

29. Zhao H, Li Q, Zhang Z, Pei X, Wang J, Li Y. Long-term ginsenoside consumption prevents memory loss in aged SAMP8 mice by decreasing oxidative stress and up-regulating the plasticity-related proteins in hippocampus. Brain Res 2009; 1256: 111-122.

30. Bergey GK, Bigalke H, Nelson PG. Differential effects of tetanus toxin on inhibitory and excitatory synaptic transmission in mammalian spinal cord neurons in culture: a presynaptic locus of action for tetanus toxin. J Neurophysiol 1987; 57(1): 121-131.

31. Korolkiewicz R, Mlynarczyk M, Gasior M, Kleinrok Z. Influence of intracerebroventricular administration of tetanus toxin on experimental seizures and protection afforded by some antiepileptic drugs in mice. Pharmacol Res 1998; 37(6): 477-483.

32. Shaw JA, Perry VH, Mellanby J. Tetanus toxin-induced seizures cause microglial activation in rat hippocampus. Neurosci Lett 1990; 120(1): 66-69.

33. Shaw JA, Perry VH, Mellanby J. MHC class II expression by microglia in tetanus toxin-induced experimental epilepsy in the rat. Neuropathol Appl Neurobiol 1994; 20(4): 392-398.

34. Bagetta G, Knott C, Nisticó G, Bowery NG. Tetanus toxin produces neuronal loss and a reduction in GABAA but not GABAB binding sites in rat hippocampus. Neurosci Lett 1990; 109(1-2): 7-12.

35. Bagetta G, Corasaniti MT, Nisticó G, Bowery NG. High vulnerability of dentate granule cells to the neuropathological effects induced by intrahippocampal injection of tetanus toxin. Neuropharmacology 1991; 30(7): 803-808.

36. Lee CL, Hannay J, Hrachovy R, Rashid S, Antalffy B, Swann JW. Spatial learning deficits without hippocampal neuronal loss in a model of early-onset epilepsy. Neuroscience 2001; 107(2): 71-84.

37. Deng W, Aimone JB, Gage FH. New neurons and new memories: how does adult hippocampal neurogenesis affect learning and memory? Nat Rev Neurosci 2010; 11(5): 339-350.

38. Lafenetre $P$, Leske $O$, Wahle P, Heumann R. The beneficial effects of physical activity on impaired adult neurogenesis and cognitive performance. Front Neurosci 2011; 5: 51.

39. Dupret D, Revest JM, Koehl M, Ichas F, De Giorgi F, Costet P, Abrous DN, Piazza PV. Spatial relational memory requires hippocampal adult neurogenesis. PLoS One 2008; 3(4): e1959.

40. Nam SM, Yoo DY, Kim W, Yoo M, Kim DW, Won MH, Hwang IK, Yoon YS. Effects of $S$-allyl-L-cysteine on cell proliferation and neuroblast differentiation in the mouse dentate gyrus. J Vet Med Sci 2011; 73(8): 1071-1075.

41. Lafenêtre P, Leske O, Ma-Högemeie Z, Haghikia A, Bichler Z, Wahle P, Heumann R. Exercise can rescue recognition memory impairment in a model with reduced adult hippocampal neurogenesis. Front Behav Neurosci 2010; 3: 34.

42. Ekdahl CT, Claasen JH, Bonde S, Kokaia Z, Lindvall O Inflammation is detrimental for neurogenesis in adult brain. Proc Natl Acad Sci U S A 2003; 100(23): 13632-13637.

43. Graciarena M, Depino AM, Pitossi FJ. Prenatal inflammation impairs adult neurogenesis and memory related behavior through persistent hippocampal TGF $\beta 1$ downregulation. Brain Behav Immun 2010; 24(8): 1301-1309. 